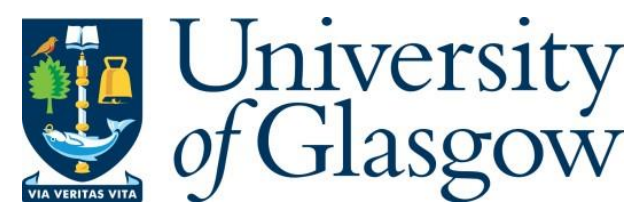

Crothers, A.J., Bagg, J. and McKerlie, R. (2017) The Flipped Classroom for pre-clinical dental skills teaching - a reflective commentary. British Dental Journal, 222(9), pp. 709713.

There may be differences between this version and the published version. You are advised to consult the publisher's version if you wish to cite from it.

http://eprints.gla.ac.uk/141462/

Deposited on: 31 May 2017

Enlighten - Research publications by members of the University of Glasgow http://eprints.gla.ac.uk 


\title{
The Flipped Classroom for Pre-Clinical Dental Skills Teaching - a Reflective Commentary
}

\begin{abstract}
A Flipped Classroom method for teaching of adult practical pre-clinical dental skills was introduced to the BDS curriculum in Glasgow during the 2015/2016 academic session. This report provides a commentary of the first years' experience, from the identification of the need to optimise teaching resources, through the planning, implementation and development of the method, with an early indication of performance.
\end{abstract}

\section{What is Flipped Learning?}

Evidence is accumulating from secondary, further and higher education that teaching techniques which combine online and face-to-face components can be more effective than either method employed alone. ${ }^{1}$ One such method is Flipped Learning, in which subject material is delivered online for review by learners prior to a class. These resources then provide the background material to inform and guide their subsequent face-to-face session with peers and tutors in the Flipped Classroom.

Originally developed from distance learning, ${ }^{2}$ Flipped Learning has been defined as:

'A pedagogical approach in which direct instruction moves from the group learning space to the individual learning space, and the resulting group space is transformed into a dynamic, interactive learning environment where the educator guides students as they apply concepts and engage creatively in the subject matter.' ${ }^{3}$

A recent review of the Flipped Classroom concept provides an excellent summary. ${ }^{4}$ This Flipped Learning and Classroom model combines both online and face-to-face instruction, aiming to create active, engaged learning in student-centred classrooms, providing a flexible working environment. Most applications of the model require the student to watch a screencast or lecture prior to the class, and then use the direct contact time with peers and tutors to engage in discussion and group work, thereby exploring and engaging with the subject in greater depth. The method has also been used to provide background and supporting information in advance of practical classes, and has been shown to have a positive effect on students' learning and improve their hands-on skills. ${ }^{5}$ Research exists to suggest that when learners are exposed to tasks, if they have previous experience of material relating to that task, recall of that material is enhanced by a mechanism known as priming. ${ }^{6}$ In this way, students accessing the online material in advance of the class are primed with background knowledge in order to carry out the practical task

By requiring thorough preparation before the laboratory class, responsibility for 
learning is the students'; this engenders a culture of personal enquiry and active engagement rather than passive acquisition of knowledge. Independent exploration of subjects in greater depth is therefore facilitated. ${ }^{7}$ There is also evidence to suggest such screencast based pre-training makes learning contextually similar new material easier. ${ }^{8}$

In summary, the fundamental idea is to move the didactic teaching outside the practical class for study and review prior to the session. In this way, the lower levels of Blooms taxonomy (remember, understand) can be moved to outside the group learning space. Students can then apply the higher levels (create, evaluate, analyse, apply) to the tasks, skills and concepts with the practical class with appropriate direction and interaction with tutors. ${ }^{9}$

Following publication of the original concept, 2 considerable development and research has been carried out within higher education. Online communities have been established so that educators may access resources themselves to develop materials, share research and give examples of good practice. ${ }^{3}$

\section{Flipped learning in healthcare education}

Not surprisingly the concept of the Flipped Classroom has been extended to medical and dental education. 10, 11, 12 Online information provided before a tutorial permits restructuring of the class, reducing or removing the need for didactic teaching during the tutorial and facilitating active learning. Classes often involve the students undertaking a team-based approach to educational activity, and evidence is now also emerging that this teaching model improves student performance in assessment. ${ }^{13}$ The model also demonstrates high degrees of acceptance with teachers and learners, resulting in more positive interactions during class time where students are more likely to engage in critical thinking. 14

\section{Traditional pre-clinical skills teaching in dentistry}

Learning clinical operative techniques can be potentially challenging for junior dental students, who may have little experience in tasks requiring manual dexterity. It is therefore essential to maximise the time students spend undertaking practical tasks in simulated clinical environments. Close guidance from tutors is required, so that students can gain core competencies before treating patients.

Traditionally, students would learn procedures such as cavity preparation by sitting with a tutor in a small group. After being taught the theory, they would watch the tutor perform the task and then attempt the procedure themselves. Over time, such teaching has been subsequently augmented with slide shows and live or recorded video demonstrations, which were shown at the beginning of a practical simulation session. The major disadvantage of this approach is that students spend a considerable amount of their time in the practical class 
passively acquiring information instead of operating on their simulators. If the didactic element of the session could be removed, this would provide valuable additional time for students to practise and develop their practical skills and for learners and teachers to interact.

\section{The Flipped Classroom for pre-clinical dental skills teaching}

In light of the comments above, the Flipped Classroom could potentially deliver significant benefits in dental education, especially where there is a requirement for tutors to interact on a one-to one basis to demonstrate skills and behaviours.

Dental students generally have a good understanding of information technology, routinely applying these skills to their personal as well as academic activities. Utilising a Flipped Learning approach to teaching early clinical skills development therefore seemed worthy of consideration. It could remove the didactic teaching and demonstrations of clinical procedures such as cavity preparation and restoration from the clinical simulation facility to online resources viewed before the class. This would allow students to maximise practical time training on their simulators, and allow tutors to have extra time to actively interact with their students in a more personally meaningful way to help manage individual progress. Any didactic material that can be delivered via electronic means can thus be removed from the class workspace, unless it is for review, discussion or answering questions.

This novel approach to teaching clinical skills in dental education has now been developed and applied at Glasgow Dental School.

\section{Development of electronic teaching resources}

Before it was possible to adopt this teaching method it was necessary to develop an extensive suite of electronic teaching resources. When developing a course of this type, the amount of time required to prepare the on-line materials must not be underestimated. For example, a twenty-minute screencast may take up to ten hours to create, though once made the material can easily be edited and use of templates can facilitate the development of new material. The entire programme must be meticulously planned in advance, with an intentional lesson plan developed for each session outlining and directing the student in the task to be undertaken. For practical skills classes, image rich presentations should describe every stage of a procedure, and links to other educational resources should be provided.

The Clinical Skills classroom audio-visual suite at Glasgow Dental School has the capability and flexibility to create high-quality media presentations in various formats, giving authenticity to the tasks the students will undertake. These teaching resources included generic material for each type of procedure to be carried out, such as a cavity preparation or restoration. Creating intentional content is important when preparing for a flipped classroom. Students must be 
told explicitly what tasks they are to carry out, so an image-rich lesson plan was produced for each classroom activity. ${ }^{3}$ A multimedia screencast was also produced for each type of clinical activity in order to consolidate content relevant to multiple classes. These productions include images, animations and audio/video recordings of clinical procedures which relate to the relevant lesson plans. It is important to create content that relates to conceptual understanding of the clinical procedure so that students gain experience in transferring skills to different situations, for example removing caries and placing restorations in different locations intraorally. Pre-produced material delivered online also has the advantage that a demonstration can be condensed into a shorter period of time through editing out any unnecessary material. A further advantage is that whilst a live demonstration by a tutor may only be viewed once by students prior to undertaking the task themselves, the online materials can be referred to on multiple occasions.

A typical online media presentation for an operative techniques class lasts between $15-20$ minutes. All material provided is integrated into the University of Glasgow virtual learning environment (VLE), Moodle (Fig. $1^{*}$ ). Students are therefore readily able to access any other content that may be relevant to the tasks to be undertaken. For example, students removing simulated caries and placing a restoration can readily access the relevant dental materials science information held on the VLE.

In addition to these specific online clinical skills resources, links to other on line educational materials are provided, such as Scottish Dental Education Online ${ }^{15}$ which provides excellent teaching resources on tooth morphology.

\section{Audio-visual and information technology requirements}

The clinical skills facility in which the Flipped Classroom teaching is delivered is fully equipped with high specification audio-visual facilities both to produce and support teaching material. All the resources covering the operative techniques course were created in a format that could be accessed as easily as possible both on the individual monitors at each workstation and online over a wide range of devices. Students are encouraged to bring their own tablets and smart phones into the classroom, allowing them to revisit or research information via the University Wi-Fi network (Fig 2*). Students may also record images of their work and subsequent feedback using their devices, and evidence of exemplary work can be uploaded to the student's web-based portfolio of academic achievement.

All of the resources are made available online at the start of the academic year, rather than being released sequentially for each class. This allows students to prepare at their own pace, identifying their own learning needs, and those wishing to see a broader context to their current class may easily do this. Students have dedicated self - instruction time allocated within the timetable to allow for differences in student preparation strategies, and review of access logs suggest that both this, and time during the evening before individual classes are used. There was however a considerable variety of access strategies, with some 
students preparing much further in advance than others. An additional advantage to preparing the material locally within the facility is that content can be made reactive to feedback (Fig $3^{*}$ ). If it transpires that students have not grasped a concept, additional material can be quickly created in response and placed online. Indeed, more material is being continually added and updated in response to student feedback.

Creation of online material does not necessarily have to be the domain of teaching staff. At Glasgow Dental School, final year students have the option of participating in a Student Selected Module in which they develop online resources in collaboration with staff members. This has already resulted in a student-produced package that will be incorporated into flipped classroom teaching of endodontics. This activity introduces the concept of staff and students working together as co-creators of the curriculum, ${ }^{16}$ providing students who are interested in both technology and dental education with a framework to develop their interests.

\section{Implementation}

At the beginning of the Pre-Clinical Skills course, a traditional lecture was given to brief the second year students on the course content and the method by which it was to be delivered. The nature of the Flipped Classroom was made explicit and the benefits outlined. It is essential that students understand the importance of self-direction in their learning, and educational support for this is provided for those who may find this more challenging than traditional didactic methods. Examples of this include the use of effective learning advisors and the student mentor system.

Staff briefing was also required. The role of the tutor changes in the Flipped Classroom in that there is, by necessity, more interaction with students. Staff were briefed in the same way as the students and encouraged to be as interactive as possible and to be reflective in their practice. Training was required for some in the use of the audio-visual suite and it is, of course, essential that the teaching staff are intimately familiar with the content of all the online material.

At the beginning of each individual class there is a brief introductory period to ensure students know what tasks they have to carry out, and to answer any questions raised by students after undertaking their prior preparation. The students then progress with tasks at their own pace, whilst simultaneously interacting with their peers, tutors and teaching material. Students who develop skills more quickly than others are free to proceed to more complex tasks at an earlier stage, provided they satisfy their teacher that they have reached the appropriate competency level. ${ }^{3,7}$ The feedback provided is therefore immediate and specific to each student.

At the end of the class there is short plenary session for discussion of the work carried out. This involves small group discussions with tutors to identify common 
issues relating to specific procedures, the sharing of experiences, the provision of individual and general two-way feedback in addition to answering further questions.

It is important to recognise that provision of online teaching material to support the Flipped Classroom does not replace staff, and for the model to function optimally there must be sufficient experienced tutors to ensure each student receives the appropriate amount of interaction and feedback during the clinical skills session.

One concern often expressed about flipping the classroom is that it is dependent on students accessing the material in advance of the class. However, experience from many educational sources suggests that this is not usually a problem. ${ }^{17}$ As described above, it is critical that students are fully informed that the course will be delivered in this way, and most dental students are usually sufficiently motivated to engage with the teaching method. Access to technology does not appear to be problematic for dental students ${ }^{18}$ so this should not be considered a barrier. All students were able to access a smartphone or tablet in class, and a personal computer at home or in the library and computer clusters. No concerns were raised in respect of access. A small minority of students elected to bring material in print form. Access logs to the VLE also confirmed that $100 \%$ of students were able to view content. Levels of engagement do vary however, and most students accessed pre-class material multiple times with only a minority accessing once or not at all for each individual class.

Those who do not engage soon realise that they will be unable to progress through a topic smoothly without accessing the online content, and if a student fails to prepare for a class, they rarely do so again.

\section{Assessment}

Assessment during the course component is primarily formative with immediate specific personalised feedback. Exercises can be repeated with appropriate further instruction if the end result would represent an adverse clinical outcome. After all exercises have been completed at the end of the course component, there is a summative assessment in a selected series of tasks - cavity preparation, cavity restoration and the safe manipulation of scaling instruments. It must be stressed that these are not competency assessments, but a gateway to the first patient contact, indicating that the student is safe to proceed.

In the near future we will be extending our use of the on line grading and feedback system from the student clinics to the Pre-Clinical Skills teaching facility. This system will allow for longitudinal monitoring of how students' skills and supporting knowledge are developing, enabling staff to identify any individuals who would benefit from closer support within the flipped classroom.

\section{Future developments}


Further enhancements of this teaching method are planned, based upon student and staff feedback. The use of online and in-class quizzes is to be expanded, with use of electronic voting for the latter via web-based software and students' own wireless enabled devices. Greater use of peer assessment is also planned so that more experienced senior students can share their own experiences with their junior colleagues in a more informal environment and they themselves gain insight into giving feedback on the work of others. Students are actively encouraged to review and discuss each other's work, and formalising this into the course component may be beneficial. Students who have uploaded exemplars of their work can easily share with each other via their electronic on line portfolio, providing an ideal medium for reflective discussion between students. The flexible learning environment of the Flipped Classroom also provides an ideal setting for peer instruction. The use of peer assisted learning where more senior students join the professional educators in the laboratory has already been explored in this respect, with senior students assisting junior students in simple tasks, allowing the educators to focus on higher level thinking and practical skills.

One other extension of the Flipped Classroom teaching concept is that of Flipped Mastery. ${ }^{19}$ In this model, rather than objectives being set for individual classes, more freedom is given to students to progress at their own pace centred around key stages of development, usually linked to staged formative assessment. By adopting this approach, students who are proficient and require less guidance develop and progress more independently, allowing teachers to focus on those who would benefit most from more personal instruction. The staging of assessments ensures that their abilities are sufficient for the student to move on to the next higher level of learning. This concept fits in well for the teaching of practical skills in that students with better manual abilities in technical exercises are not held back by those who require more instruction. Plans to trial this approach are in progress and the online grading and assessment tool will allow students and teachers to monitor skills development and progression.

\section{Conclusions}

Early experience in Glasgow Dental School has demonstrated many advantages of this model of pre-clinical skills teaching as reflected in very positive feedback from students in the end of year course evaluation. Thirty-three students responded to the end of course survey and free-form comments indicated that students particularly appreciated being able to prepare in advance of classes as exemplified by these two quotes:

"I feel this is a fantastic idea which has worked tremendously well. Anything confusing to a student, they could just study in advance or ask a peer for help. It also saved a lot of time and gave us more practical practice in each session, and I feel the operative techniques course should (and was) focussed on this practical experience."

"I liked this method of teaching. It allowed me to do some further reading before attending the class and prevents lots of clueless 
The video materials were considered invaluable, as they could be reviewed on multiple occasions, and at a time and place to suit students' own learning patterns. The students also commented favourably on having the extra time to carry out the practical classes. Having all the material for the course delivered far in advance to put each lesson into context was also very well received. It is also evident that the students used the online material extensively in preparation for their professional examinations. The few negative comments centred on the inability to ask questions during the online presentations. In the original student briefing prior to the course, students were encouraged to seek out answers to any questions themselves prior to attending classes, and reassured that any outstanding queries would be addressed then. It may be that some students have less experience of independent methods of study and require more support in this respect.

Whilst this paper has concentrated on the role of the flipped classroom in delivering pre-clinical skills training, there are many other aspects of dental education that could benefit from the approach. We already use it for the teaching of histopathology via clinical scenarios supported by virtual microscopy (paper in preparation) and have just introduced an element of flipped classroom to Oral Biology teaching in BDS 1. The latter will also ensure that students are familiar with the flipped classroom concept before they commence pre-clinical skills training in BDS 2.

In summary, the initial setting up of the course has required considerable time and effort, but now the resources have been developed they can be easily maintained, updated and modified in response to feedback. For those interested in adopting this approach, the importance of recognising the time and resource implications for developing the teaching materials and the need to ensure that both students and staff are fully briefed on their roles and responsibilities during both class preparation and practical sessions are essential. It is important to stress that it is not simply the online delivery of material that is important - it is what providing these resources enables in the Flipped Classroom. The primary benefit has been the increased time that tutors are able to spend with individual students learning practical operative dentistry at the start of their clinical studies. Students are encouraged to take ownership of both the development of their practical skills and the necessary underpinning knowledge required to support it. In this way, independence in learning, an important graduate attribute, is engendered early in students' studies, allowing them to develop their practical and academic abilities in a supportive and flexible environment. 


\section{References:}

1. U.S. Department of Education, Office of Planning, Evaluation, and Policy Development. Evaluation of evidence-based practices in online learning: a meta-analysis and review of online learning studies. 2010. Online information available at: www2.ed.gov/rschstat/eval/tech/evidencebased-practices/finalreport.doc (accessed June 2016).

2. Bergmann J, Sams A. Flip your Classroom: Reach Every Student in Every Class Every Day. ISTE-ASCD, 2012.

3. Flipped Learning Network (FLN). (2014) The four pillars of F-L-I-PTM What Is Flipped Learning? Online information available at: http://flippedlearning.org/wpcontent/uploads/2016/07/FLIP handout FNL Web.pdf (accessed September 2014).

4. Rotellar C, Cain J. Research, Perspectives, and Recommendations on Implementing the Flipped Classroom. American Journal of Pharmaceutical Education 2016;80(2) Article 34.

5. N Warter-Perez, J Dong. Flipping the Classroom: How to embed enquiry and design projects into a digital engineering lecture 2012 Proceedings of the 2012 ASEE PSW Section Conference. Online information available at: http://aseepsw2012.calpoly.edu/site media/uploads/proceedings/papers L10B 35 ASEE PSW 2012 Warter-Perez.pdf (accessed June 2016).

6. Bodie G D, Powers W G, Fitch-Hauser M. Chunking, priming and active learning: Toward an innovative and blended approach to teaching communication-related skills. Interactive Learning Environments 2006; $14: 2,119-135$.

7. Michael, J. Where's the evidence that active learning works? Advances in Physiology Education 2006; 30,159-167.

8. Musallam, Ramsey, Ed.D. The effects of using screencasting as a multimedia pre-training tool to manage the intrinsic cognitive load of chemical equilibrium instruction for advanced high school chemistry students. PhD thesis University of San Francisco, 2010.

9. Anderson L, Krathwohl D R. A taxonomy for learning, teaching, and assessing: A revision of Bloom's taxonomy of educational objectives. Allyn and Bacon. Boston, MA (Pearson Education Group) 2001.

10. Morgan H, McLean K, Chapman C, Fitzgerald J, Yousuf A, Hammoud M. The flipped classroom for medical students. The Clinical Teacher 2015;12: 155-160. 
11. McLaughlin J, Roth $M T$, Glatt D M, et al. The Flipped Classroom: A Course Redesign to Foster Learning and Engagement in a Health Professions School. Academic Medicine 2014; 89, (2): 236-243.

12. Park $S E$, Howell $T H$. Implementation of a Flipped Classroom Educational model in a Predoctoral Dental Course. Journal of Dental Education 2015; 79(5): 563-570.

13. Tune J D, Sturek M, Basile D P. Flipped classroom model improves graduate student performance in cardiovascular, respiratory, and renal physiology. Advances in Physiology Education 2013; 37, (4): 316-320.

14. Driscoll T. 2012. Flipped Learning \& Democratic Education: The Complete Report. Online information available at: http://www.flippedhistory.com/2012/12/flipped-learning-democratic-education.html. (accessed June 2016).

15. Scottish Dental Education Online. Online information available at https://www.sdeo.ac.uk/. (accessed June 2016).

16. Bovill C. Students and staff co-creating curricula: an example of good practice in higher education? In Dunne, E. and Owen, D. (eds.) The Student Engagement Handbook: Practice in Higher Education. pp. 461476. Emerald, 2013.

17. Yarbro J, Arfstrom K M, McKnight $\mathrm{K}$ et al. Extension of a Review of Flipped Learning 2014. Online information available at: http://flippedlearning.org/wp-content/uploads/2016/07/Extension-ofFLipped-Learning-LIt-Review-June-2014.pdf (accesses June 2014).

18. Mehta, S. Clarke, F. Fleming P.S. An assessment of student experiences and learning based on a novel undergraduate e-learning resource. British Dental Journal 2016; 221(3):131-140.

19. Bergmann J, Sams A. Flipping for Mastery. Educational Leadership 2013; 71(4): 24-29.

Acknowledgements

The authors would like to acknowledge: Christopher Kennedy for his technical assistance in the production of the video resources and Niall Rogerson who provided peer feedback on the resources produced.

\section{*Legend for Fig 1: Screenshot of the Glasgow VLE \#Legend for Fig 2: Students using the Facilities AV system and their own devices during a class ₹Legend for Fig 3: The feedback cycle for the Flipped Learning model}


BDS2: Clinical Dental Sciences (CDS) Home Page

Welcome to the Clincal Dental Sciences Home Page for BDS2 students.

酋 Clinical Dental Sciences News forum

CDS: Operative Dentistry

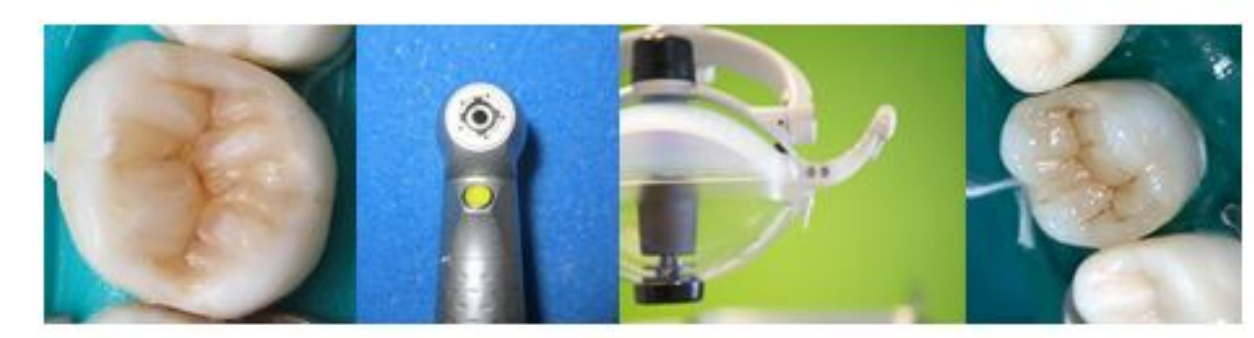

This area contains resources you will need to access in support of you classes in Operative Techniques

Operative Techniques: General Information and Resources

Lesson Plans, Lecture Handouts, Video demonstrations and other resources can be found here.

Operative Techniques Class Feedback Forum (Live)

5 Use this Forum to post questions during a class for discussion whist working. Please use your mobile device for this.

Make sure you check the 'Mail now' tickbox when posting.

Overview of Clinical Skills Sessions

Lesson Plans

Lecture Handouts

Tooth Morphology Guide

This guide will help you when recreating occlusal surfaces and also give you an indication where the pulp is likely to be when preparing a cavity

르. Video- Introduction and Tasks

Please watch this presentation before attending Session 1

Eideo - Dental Dam Placement

Please watch this presentation before attending Session 2

들 Video-Occlusal Caries
CDS: Periodontology

\section{it. Activities \\ Assignments \\ ? Choices \\ \& Feedback \\ Forums \\ $\nabla$ Quizzes \\ Pesources}

\section{Search forums}

曰

\section{co}

Advanced search (?)

\section{$\checkmark$ Latest announcements}

Add a new topic.

(No news has been posted yet)

\section{Upcoming events}

曰

There are no upcoming events

Go to calendar...

New event..

\section{My courses}

Scottish Dental Education Online ;

E-Learning Resources

BDS Handbook

BDS Restorative Dentistry Clinical

Synopsis

BDS1: Clinical Dental Sciences 2016/17

BDS1: Administration 2015/16

BDS1: Clinical Dental Sciences 2015/16 


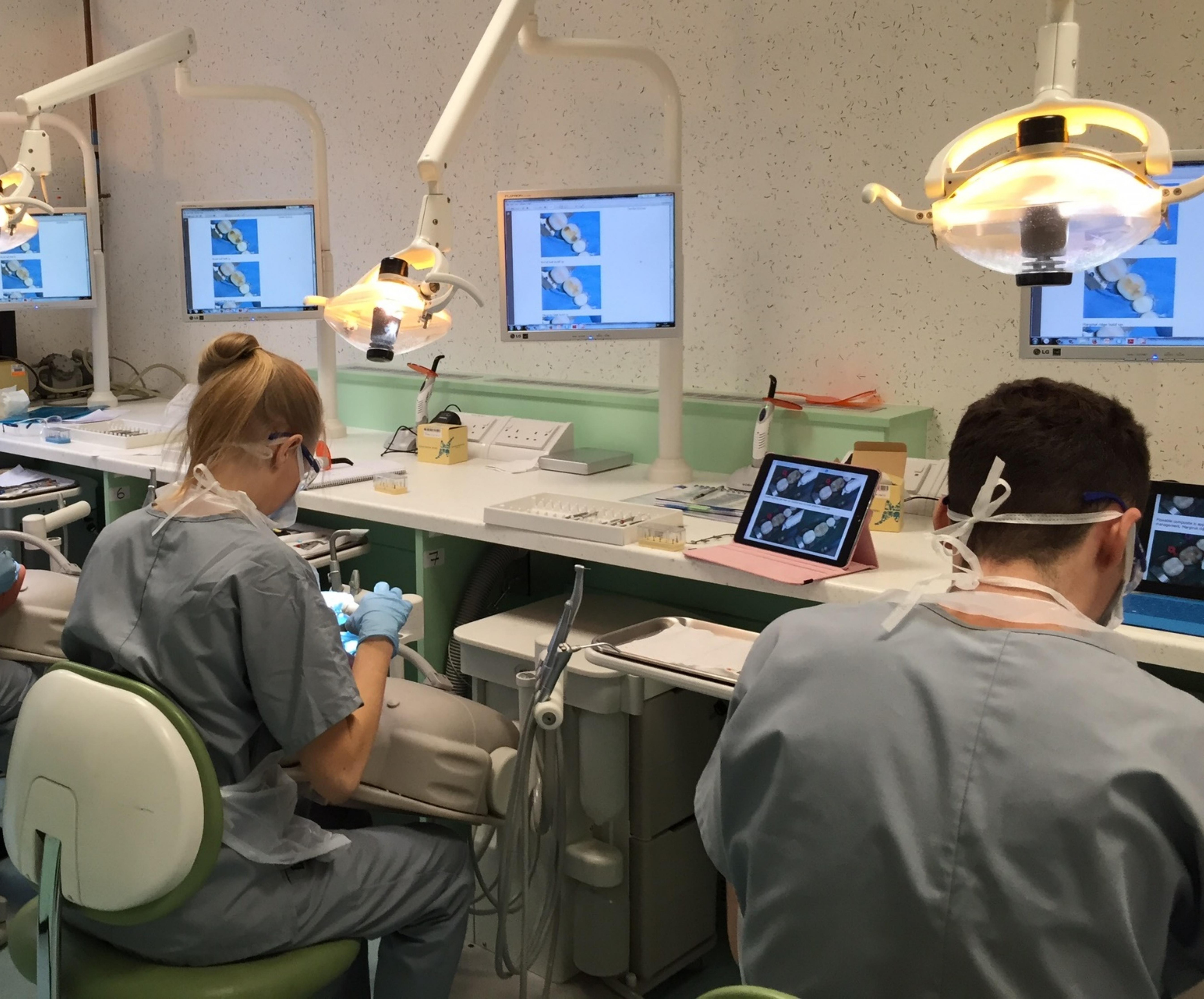




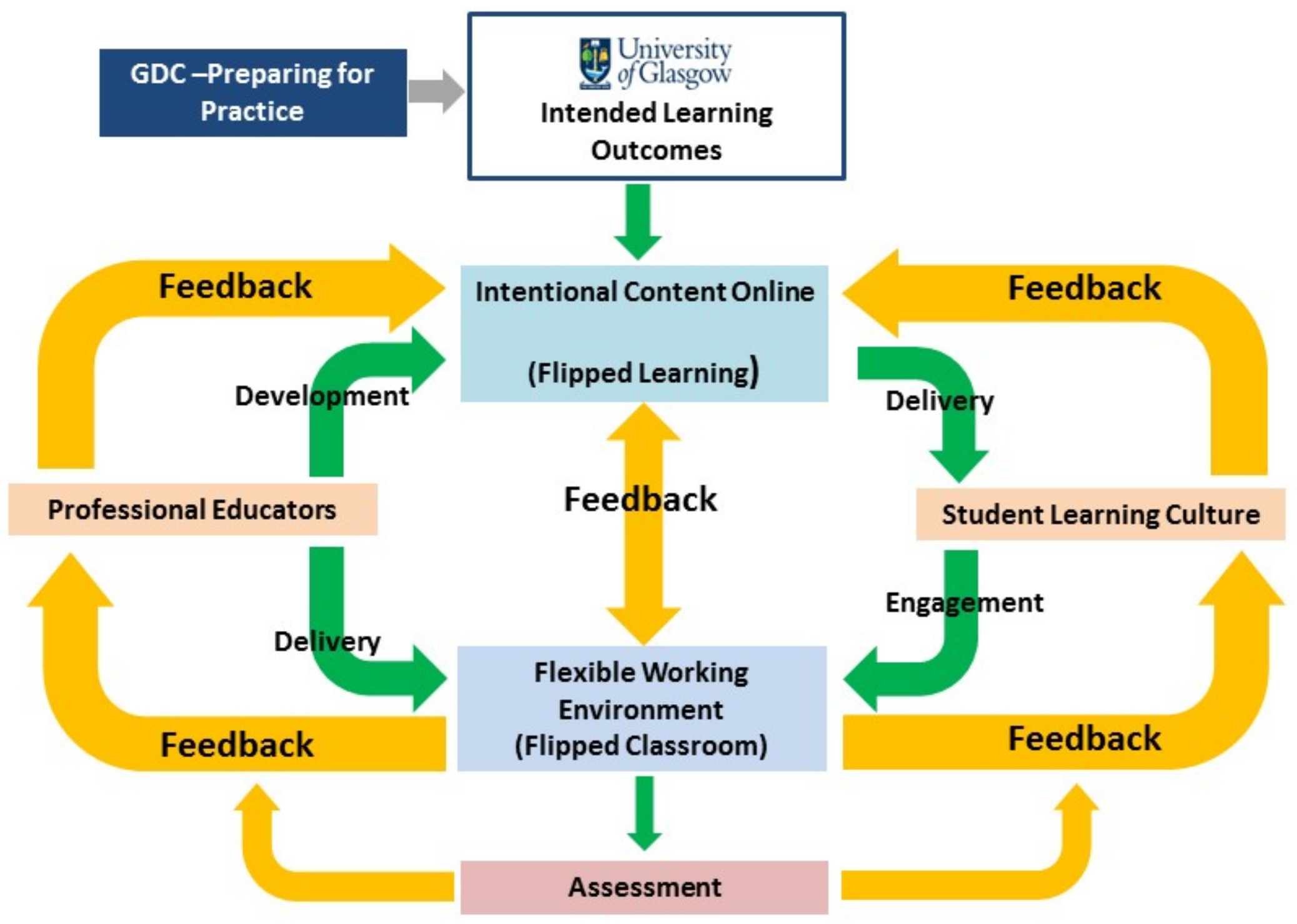

